\title{
Cortical thickness changes following spatial navigation training in adulthood and aging
}

\author{
Elisabeth Wenger ${ }^{\text {a,* }}$, Sabine Schaefer ${ }^{\text {a }}$, Hannes Noack ${ }^{\text {a }}$, Simone Kühn ${ }^{\text {b,c }}$, Johan Mårtensson ${ }^{\text {d }}$, \\ Hans-Jochen Heinze e,f, Emrah Düzel ${ }^{\text {e,f,g }}{ }^{\text {, Lars Bäckman }}{ }^{\mathrm{h}}$, Ulman Lindenberger a ${ }^{\text {, Martin Lövdén }}{ }^{\text {a,d,h,* }}$ \\ a Center for Lifespan Psychology, Max Planck Institute for Human Development, Germany \\ ${ }^{\mathrm{b}}$ Department of Experimental Psychology, Ghent University, Belgium \\ c Charité University Medicine, St. Hedwig Krankenhaus, Berlin, Germany \\ d Department of Psychology, Lund University, Sweden \\ e Department of Neurology, Otto-von-Guericke University of Magdeburg, Germany \\ ${ }^{\mathrm{f}}$ DZNE (German Centre for Neurodegenerative Disorders), Magdeburg, Germany \\ ${ }^{\mathrm{g}}$ Institute of Cognitive Neuroscience, University College London, UK \\ ${ }^{\text {h }}$ Aging Research Center, Karolinska Institutet, Sweden
}

\section{A R T I C L E I N F O}

\section{Article history:}

Received 29 June 2011

Revised 29 October 2011

Accepted 4 November 2011

Available online 12 November 2011

\section{Keywords:}

Cortical thickness

Plasticity

Spatial navigation

Aging

\begin{abstract}
A B S T R A C T
A widespread network involving cortical and subcortical brain structures forms the neural substrate of human spatial navigation. Most studies investigating plasticity of this network have focused on the hippocampus. Here, we investigate age differences in cortical thickness changes evoked by four months of spatial navigation training in 91 men aged 20-30 or 60-70 years. Cortical thickness was automatically measured before, immediately after, and four months after termination of training. Younger as well as older navigators evidenced large improvements in navigation performance that were partly maintained after termination of training. Importantly, training-related cortical thickening in left precuneus and paracentral lobule were observed in young navigators only. Thus, spatial navigation training appears to affect cortical brain structure of young adults, but there is reduced potential for experience-dependent cortical alterations in old age.
\end{abstract}

(c) 2011 Elsevier Inc. All rights reserved.

\section{Introduction}

Successful navigation draws on deriving spatial information from multiple sensory cues, creating and maintaining accurate spatial representations in short- and long-term memory, as well as using and manipulating these representations to guide behavior (Wolbers and Hegarty, 2010). Consequently, a widespread network of brain structures is involved in spatial navigation. The hippocampus, caudate nucleus, parahippocampal gyrus, posterior cingulate gyrus, cuneus, precuneus, parietal lobe, and prefrontal cortex constitute neural underpinnings of human spatial navigation (Aguirre et al., 1996; Grön et al., 2000; Moffat et al., 2006; O'Keefe and Nadel, 1978).

The hippocampus and the parahippocampal gyrus play central roles in allocentric (i.e., world centered) spatial processing, whereas the parietal cortex and the caudate nucleus support egocentric (i.e., body centered) representations of locations (Becker and Burgess, 2001; Iaria et al., 2003; Maguire et al., 1998). Allocentric representations are mainly generated by so-called place cells in the hippocampus

\footnotetext{
* Corresponding authors at: Center for Lifespan Psychology, Max Planck Institute for Human Development, Lentzeallee 94, 14195 Berlin, Germany. Fax: + 49308249939.

E-mail addresses: Wenger@mpib-berlin.mpg.de (E. Wenger), Loevden@mpib-berlin.mpg.de (M. Lövdén).
}

that continuously update the individual's position in space via firing of networks of cells responsive to spatial location (Ekstrom et al., 2003; O'Keefe and Burgess, 1996). Egocentric representations are thought to be based on neurons in the medial parietal area (precuneus) that encode the distance and directions of environmental landmarks, whereas the posterior parietal cortex may be involved in translating egocentric into allocentric information and vice versa (Burgess et al., 2001). Structural and functional individual differences in the hippocampus and caudate nucleus also co-vary with between-person differences in navigational strategy. For example, Bohbot et al. (2007) found that allocentric learners have significantly more gray matter in the hippocampus and less gray matter in caudate nucleus relative to egocentric learners. Lerch et al. (2011) have shown that mice trained on a spatial variant of a maze that requires allocentric strategies show growth restricted to the hippocampus, whereas mice trained on a cued version of the maze that facilitates egocentric strategies show growth in the striatum. Thus, navigational learning may induce structural brain changes in a use-dependent way.

Spatial navigation performance is highly vulnerable to aging. Older rats are generally impaired in navigation performance compared to younger rats (Barnes, 1979; Begega et al., 2001; Ingram, 1988; McLay et al., 1999), and younger adults outperform their older counterparts in spatial navigation tasks (Driscoll et al., 2005; Lövdén et al., 2005b; 
Mahmood et al., 2009; Moffat et al., 2001; Newman and Kaszniak, 2000; Wilkniss et al., 1997). Functional imaging studies have shown that older adults exhibit reduced hippocampal activation during navigation tasks compared to younger adults (Antanova et al., 2009; Moffat et al., 2006), which is consistent with findings suggesting that older adults rely more on egocentric processes (Lövdén et al., 2005a; Rodgers et al., in press). In line with these patterns, older adults report avoiding unfamiliar routes and places (Burns, 1999), which may lead to a less engaged lifestyle that in turn further affects cognitive performance in old age (Hertzog et al., 2009; Lövdén et al., 2005a).

With some exceptions (Bohbot et al., 2011; Iaria et al., 2003; Moffat et al., 2006, 2007), investigations into the plasticity of spatial navigation performance and its underlying neural substrates have predominantly focused on the hippocampus. This is probably due to the prominent role of the hippocampus in models of spatial memory (e.g., Bird and Burgess, 2008; Hartley et al., 2007; Moffat et al., 2006) and because the hippocampus is a highly plastic brain region (e.g., Kempermann et al., 2002; van Praag et al., 2000). For example, Maguire et al. $(2000,2006)$ reported cross-sectional data demonstrating larger posterior and smaller anterior hippocampal volumes of London taxi drivers compared to controls. We have reported that prolonged spatial navigation training can protect hippocampal integrity against agerelated decline (Lövdén et al., in press). In that study, younger and older men navigated in a virtual environment while walking on a treadmill for 50 min every other day over a four-month period. Younger and older participants displayed stable hippocampal volumes both during training as well as four months after termination of training, whereas participants in a walking-only control group showed rates of decrease in hippocampal volume that approximated longitudinal observations of normal age-related decline (e.g., Raz et al., 2005).

Although this focus on the plasticity of the hippocampus and its involvement in spatial navigation performance is warranted, findings on cortical involvement in navigation and on age differences therein (Ghaem et al., 1997; Maguire et al., 1998; Moffat et al., 2007; Wolbers et al., 2007) should not be overlooked. Also, reports of experiencedependent alterations in gray matter structure of cortical brain regions (Draganski et al., 2004; Ilg et al., 2008) underscore the importance of examining cortical correlates of experience-dependent changes in spatial navigation performance. Here, we extend the analyses reported by Lövdén and colleagues, which focused on manually segmented hippocampal volumes (Lövdén et al., in press; see also Lövdén et al., 2011), by investigating whether spatial navigation training evokes changes in cortical thickness. We present results from the same longitudinal study with 4 months of spatial navigation training administered to younger and older men. Cortical reconstruction and volumetric segmentation of MR images, collected before, immediately after, and four months after termination of training, was performed with the FreeSurfer image analysis suite (http://surfer.nmr.mgh.harvard.edu/). We hypothesized that spatial navigation training, which requires both allocentric and egocentric processing, induces regional changes in cortical thickness of brain areas supporting spatial navigation. Given that animal models point to decrements in the capacity for adaptive cortical changes with advancing age (Gruntzendler et al., 2002; Mizhari and Katz, 2003; Trachtenberg et al., 2002; Wagner et al., 2000), we further predicted that navigationinduced cortical thickening would be less pronounced in older than in younger adults.

\section{Methods}

\section{Participants}

In total, 118 volunteering men were recruited through newspaper advertisements, word-of-mouth recommendation, and flyers circulated in Berlin, Germany. Participants were all right-handed, had normal or corrected-to-normal vision, reported no history of cardiovascular disease (except treated hypertension), neurological or psychiatric conditions, problems hindering gait or balance, or drug/alcohol abuse. They also reported no use of anti-seizure or antidepressant drugs. Twelve participants were excluded due to brain pathology (e.g., infarcts, large whitematter lesions) and six other participants were excluded due to imaging artifacts (e.g., movement). Nine participants dropped out during the study after pretest due to lack of motivation, health, or other personal issues.

Thus, the effective sample consisted of 44 younger participants aged $20-30$ years $(M=26.0 ; S D=2.8)$ and 47 older participants aged $60-70$ years $(M=65.0 ; S D=2.8)$. After completion of pretest, participants were matched on Digit Symbol performance (Wechsler, 1981) and age within each age group, and then randomly assigned to either a navigation group $\left(n_{\text {young }}=23 ; n_{\text {old }}=23\right.$ ) or a walk-time-yoked control group ( $n_{\text {young }}=21 ; n_{\text {old }}=24$ ). The unequal effective sample sizes reflect unequal dropout after pretest. Table 1 summarizes descriptive findings for all participants and the time between pretest and posttests.

Participants were paid 1150 Euro for completion of the whole study. The ethical review board of the Otto-von-Guericke University of Magdeburg approved the imaging part of the study, and the ethical review board of the Max Planck Institute for Human Development, Berlin approved the behavioral part of the study. Written informed consent was obtained prior to the investigation.

\section{Study design}

A detailed description of the study design has been reported elsewhere (see Lövdén et al., in press, 2011). In short, participants in the navigation group performed a navigation task in a virtual environment of a zoo while walking on a treadmill at their own preferred speed. Participants in the control group walked the exact same amount of time on a treadmill but without the navigation task. After pretest and before posttest 1, participants completed 42 training sessions. Each training session lasted $50 \mathrm{~min}$. Pretest was completed immediately before and posttest 1 immediately after the training period. The time elapsing between pretest and posttest 1 was on average 118 days. After a mean of additional 121 days without training, participants completed posttest 2 .

\section{Spatial navigation training}

Participants in the navigation group were asked to navigate through a virtual zoo via pressing one of two buttons (to navigate left or right; see Fig. 1). In each trial, participants had to find 14 animals that were successively shown in the right corner of the screen. After having found all 14 animals as fast as possible, participants had to find the exit of the zoo. Feedback about performance was provided after each trial. There were always 4 trials in the same zoo, in which participants had to find the same animals, but in a different order. Afterwards, participants were presented with a new zoo with different animals and street layout and had to orient themselves anew. The subsequent training session started at the exact final position of the previous session. The complex layout of the virtual zoos prevented participants from being able to walk through one zoo in only one session. In sum, we constructed 20 different training zoos. All participants were presented with the zoos in the same order. Depending on their performance, they completed different numbers of zoos in the course of 42 training sessions. At the beginning of training, participants were instructed to choose their own preferred speed, which was then kept constant over the training period. Training groups did not differ significantly in their mean walking speed ( $t s<.81$ ).

At pretest, posttest 1 , and posttest 2 , navigation performance of all participants was assessed with a task similar to that used in the navigation training. At all three main measurement points, magnetic resonance images (MRI) were also obtained. 
Table 1

Sample descriptives as a function of age and training group.

\begin{tabular}{|c|c|c|c|c|c|c|c|c|}
\hline \multirow[t]{3}{*}{ Measure } & \multicolumn{4}{|c|}{ Younger (20-30 years) } & \multicolumn{4}{|c|}{ Older (60-70 years) } \\
\hline & \multicolumn{2}{|c|}{ Navigators } & \multicolumn{2}{|c|}{ Walkers } & \multicolumn{2}{|c|}{ Navigator } & \multicolumn{2}{|c|}{ Walkers } \\
\hline & $M$ & $S D$ & $M$ & $S D$ & $M$ & $S D$ & $M$ & $S D$ \\
\hline Age (years) & 25.1 & 2.8 & 27.0 & 2.5 & 65.3 & 2.8 & 64.6 & 2.9 \\
\hline DS & 57.2 & 11.1 & 57.5 & 12.1 & 42.0 & 6.8 & 37.8 & 9.8 \\
\hline Vocabulary & 30.0 & 2.7 & 30.5 & 3.2 & 32.2 & 1.8 & 31.6 & 2.1 \\
\hline Raven's matrices & 9.5 & 4.2 & 10.3 & 3.2 & 4.5 & 2.3 & 4.4 & 3.0 \\
\hline Navigation performance & 20.9 & 6.1 & 21.9 & 4.6 & 7.6 & 2.9 & 8.8 & 2.7 \\
\hline Days between pretest and posttest 1 & 118 & 4.6 & 117 & 4.6 & 115 & 5.0 & 118 & 5.4 \\
\hline Days between posttest 1 and posttest 2 & 121 & 6.2 & 123 & 6.4 & 122 & 2.8 & 120 & 7.1 \\
\hline
\end{tabular}

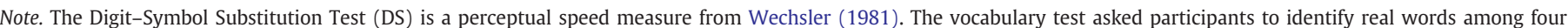

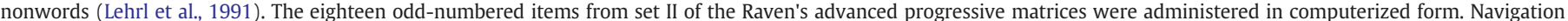
performance denotes the number of animals found within $50 \mathrm{~min}$ in the virtual zoo at pretest.

\section{MRI acquisition}

High-resolution $\mathrm{T}_{1}$-weighted images were acquired on a 3 Tesla Magnetom Trio tomograph (Siemens, Erlangen, Germany), with an 8-channel phased-array head coil. We used an MPRAGE sequence (TE $=5.12 \mathrm{~ms}$, $\mathrm{TR}=2600 \mathrm{~ms}, \mathrm{TI}=1100 \mathrm{~ms}$, flip angle $=7^{\circ}$, bandwidth $=140 \mathrm{~Hz} /$ pixel, matrix $=320 \times 320 \times 240$, isometric voxel size $=0.8 \mathrm{~mm}^{3}$ ).

\section{MRI image processing / reconstruction}

Cortical reconstruction and volumetric segmentation was performed with the FreeSurfer image analysis suite (http://surfer.nmr. mgh.harvard.edu/). The technical details of these procedures have been described thoroughly elsewhere (Dale et al., 1999; Fischl et al., 2004a, 2004b; Han et al., 2006; Jovicich et al., 2006; Segonne et al., 2004). Briefly, this program uses intensity and continuity information from MR volumes to reconstruct and measure cortical thickness, and provides valid measures at submillimeter resolution (Fischl and Dale, 2000; Kuperberg et al., 2003; Rosas et al., 2002; Salat et al., 2004). Assessments of test - retest reliability of FreeSurfer have revealed high intra-class correlations of .994 for MPRAGE sequences (Wonderlick et al., 2009) and high consistency of absolute within-subject measures of cortical thickness assessed in intervals of minutes to weeks with variations of only $\leq .05 \mathrm{~mm}$ (Wang et al., 2008).

\section{FreeSurfer protocol}

All reconstructed data were visually checked for segmentation accuracy at each time point. No manual interventions with the MRI data were performed.

We used the longitudinal processing scheme implemented in FreeSurfer to incorporate the subject-wise correlation of longitudinal data into the processing stream. All three time points were first processed with the cross-sectional stream. Then, a base template was created from all three time points, which operates as an initial estimate for the segmentation and surface reconstruction. The three measurement time points were then registered to this template to ensure non-biased analysis with regard to the three time points. This work flow significantly reduces the variability of results across time points and thus increases the robustness and sensitivity of the overall longitudinal analysis, thereby also improving the likelihood to detect subtle changes (Han et al., 2006).

We then computed thickness difference maps by subtracting the longitudinally processed time point 1 image from the longitudinally processed time point 2 image and time point 3 image, respectively. The two resulting difference maps for each individual were then resampled, mapped onto a common surface, and smoothed with a $10 \mathrm{~mm}$ FWHM isotropic Gaussian kernel.

\section{Statistical analyses}

Navigation performance was analyzed with a mixed 3-way analysis of variance (ANOVA) with training group (navigators, controls), age group (young, old), and time (pretest, posttest 1, posttest 2) as factors. The alpha level for all analyses conducted in SPSS was set to $p=.05$.

The cortical thickness difference maps (posttest 1-pretest; posttest 2-pretest) were first analyzed with a vertex-wise general linear model (GLM: one-sample $t$-test) to assess regional changes in cortical thickness separately in all four groups (young navigators, young controls, old navigators, old controls). We applied a statistical threshold of $p<.05$, corrected for multiple comparisons by means of False Discovery Rate (FDR), with a cluster extent threshold of 150 vertices. To ascertain that any lack of effects in the old groups did not arise from a combination of sub-threshold increases in the old navigation group and decreases in the old control group, we additionally applied a more lenient and thus explorative threshold to probe for cortical thickness changes in the elderly group $(p<.001$, uncorrected), with again a cluster extent threshold of 150 vertices to only report trustworthy clusters of considerable size. Significant clusters were then treated as regions of interest (ROIs), traced in tksurfer and exported to SPSS. To determine whether changes were selective for the navigators, differences in cortical thickness between time points were compared across training groups using independent t-tests. Finally, ROI data from all three time points were analyzed with a mixed 3-way ANOVA, with training group, age group, and time as factors, to directly compare navigation to control groups and test for age differences in training-related thickness effects. To trace the source of interactions, the ROI data for younger and older adults were also analyzed separately with mixed 2-way ANOVAs, using training group and time as factors.

To investigate brain-behavior associations, we computed correlations between improvements in navigation performance (posttest 1-pretest) and changes in the extracted ROIs, using the Pearson's correlation coefficient $(p<.05)$. We also computed correlations between improvements in navigation performance (i.e., posttest 1 -pretest) and the vertex-wise whole-brain changes (posttest 1-pretest) in cortical thickness to probe for whether other possible regions of change were correlated with behavioral improvement. Specifically, we used the behavioral improvement in navigation performance as a predictor in the vertex-wise GLM (one-sample $t$-test) analysis of the cortical thickness difference maps of the navigation groups $(p<.05$, FDR) implemented in FreeSurfer. In addition, we performed correlational analyses between cortical thickness at pretest and spatial navigation performance at pretest, posttest 1 , and the change in performance from pretest to posttest 1, using the Qdec application in FreeSurfer $(p<.05$, FDR $)$. This was done to test for possible cross-sectional differences in cortical thickness that could potentially be related to spatial navigation performance. 

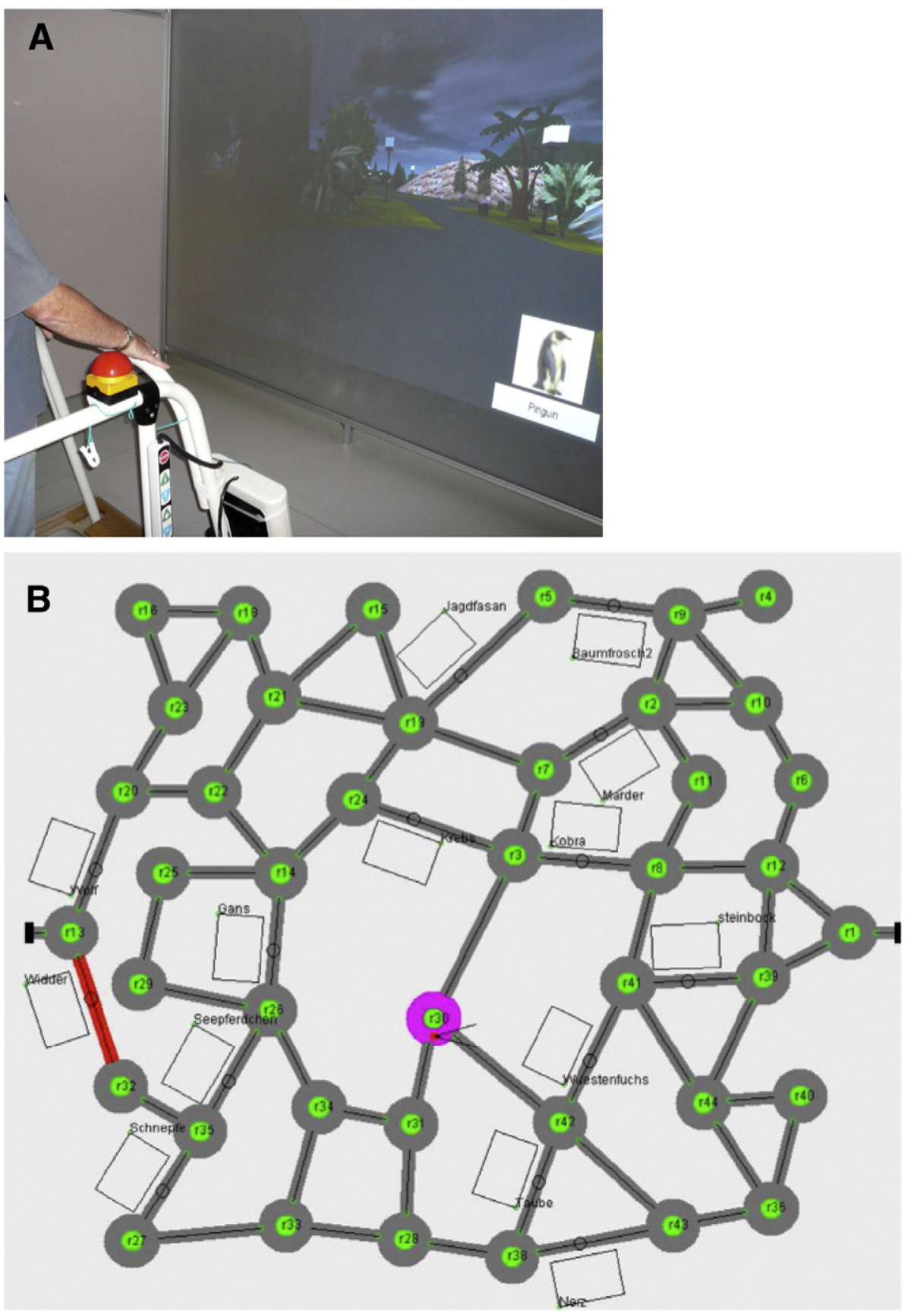

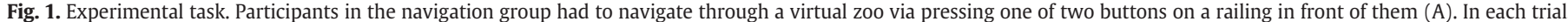

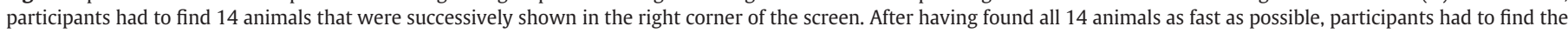

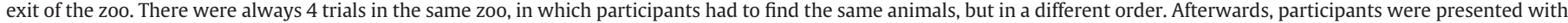
a new zoo with different animals and street layout and had to orient themselves anew in the complex layout of another virtual zoo (B).

\section{Results}

\section{Behavioral results}

As reported elsewhere (Lövdén, et al., in press), analyses of navigation performance (see Fig. 2 ) revealed significant main effects of training group, $F(1,87)=36.57, p<.05$, partial eta-squared $\left(\eta_{\mathrm{p}}^{2}\right)=.30$, age group, $F(1,87)=173.07, p<.05, \eta_{\mathrm{p}}^{2}=.66$, and time, linear $\mathrm{F}(1,87)=102,89$, $p<.05, \eta_{p}^{2}=.54$, and quadratic $F(1,87)=64,78, p<.05, \eta_{p}^{2}=.43$. These main effects were qualified by linear, $F(1,87)=40.18, p<.05, \eta_{\mathrm{p}}^{2}=.32$, and quadratic, $F(1,87)=55.41, p<.05, \eta_{\mathrm{p}}^{2}=.39$, time $\times$ training group interactions. Navigators gained more in performance than controls. Training-related performance gains were partly maintained 4 months after termination of training but, as shown by the significant quadratic time $\times$ training group interaction, they were reduced in magnitude. In addition, the linear time $\times$ age group interaction was significant, $F(1,87)=4.16, p<.05, \eta_{\mathrm{p}}^{2}=.05$, reflecting slightly greater changes over time for older compared to younger adults. However, the linear age group $\times$ training group $\times$ time interaction did not approach significance ( $p>.05)$, indicating similar performance gains from navigation training in both age groups (Fig. 2).

\section{Cortical thickness changes}

We found significant regional increases in cortical thickness between pretest and posttest 1 for young navigators in left precuneus 


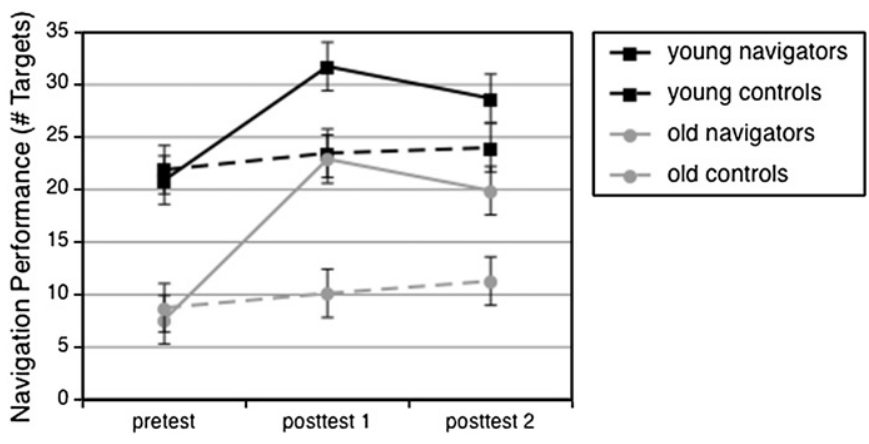

Fig. 2. Behavioral performance improvement. Mean $( \pm S E)$ navigation performance (number of targets found within 50 min of navigation) of young and old navigation and control groups before and after training.

(Talairach coordinates at peak vertex: $-7,-48,50$; Brodmann Area (BA) 7), left superior parietal lobule (peak vertex at $-32,-47,59$; BA 7) and left paracentral lobule (peak vertex at: $-5,-32,58$; BA $5 ; p<.05$, corrected using FDR). No statistically reliable thickening or thinning was observed in any other brain region. There were no significant changes in cortical thickness in young controls or in either older group. At the more lenient uncorrected threshold of $p<.001$, there were again no cortical thickness changes in old navigators or young controls, but one significant cluster of decrease in old controls in right middle frontal gyrus (peak vertex at: 40, 30, 16; BA 46; see Fig. 4).

To further investigate the increases in young navigators, we extracted the mean changes in the three ROIs and compared the cortical thickening in young navigators to young controls. Young navigators exhibited a significantly greater thickness difference in left precuneus, $t(42)=3.43, p<.05$, Cohen's $d=1.06$, and left paracentral lobule, $t(42)=3.12, p<.05, d=.96$, between pretest and posttest 1 than young controls (see upper half of Fig. 5). This difference in cortical thickness between young navigators and young controls was no longer reliable at posttest 2 (precuneus: $t(42)=.54, n s$; paracentral lobule: $t(42)=-.11, n s)$. The cortical thickening in left superior parietal lobule between pretest and posttest 1 was not significantly greater in young navigators than in young controls, $t(42)=1.42, p=.16$, and hence is not discussed further. The other two clusters that survived the comparison to the control group are depicted in Fig. 3.

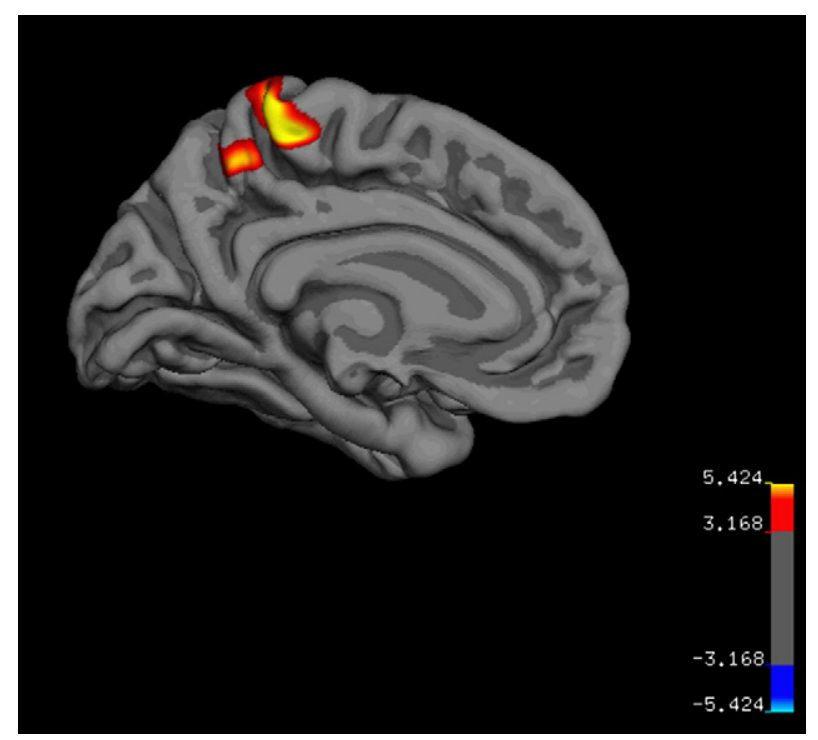

Fig. 3. Cortical thickness changes. Significant regional increases in cortical thickness between pretest and posttest 1 in young navigators in left precuneus $(-8 ;-47,50$; BA 7$)$ and left paracentral lobule $(-6,-37,66$; BA 5; FDR $p<.05)$.

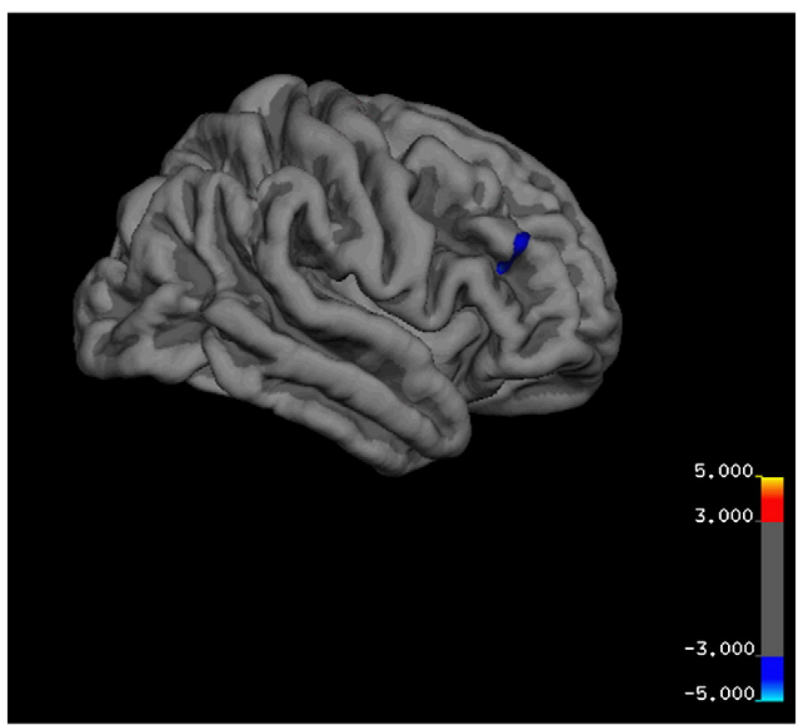

Fig. 4. Cortical thinning. Significant regional decrease in cortical thickness in old controls in right middle frontal gyrus $(40,30,16$; BA46) at $p<.001$, uncorrected, with a cluster extent threshold of 150 vertices.

In older adults, navigators and controls did not show significant differences in their cortical thickness over time, neither in precuneus (posttest 1-pretest: $t(45)=-1.64, n s$; posttest 2-pretest: $t(45)=$ $-.69, n s$ ) nor in paracentral lobule (posttest 1-pretest: $t(45)=$ $-.11, n s$; posttest 2-pretest: $t(45)=-.27$, ns; see Fig. 5).

A mixed 3-way ANOVA, with training group, age group, and time as factors on the extracted ROI data confirmed this pattern with a significant quadratic time $\times$ training group interaction for left precuneus, $F(1,87)=10.24, p<.05, \eta_{\mathrm{p}}^{2}=.10$, and a significant quadratic time $\times$ training group $\times$ age group interaction in paracentral lobule, $F(1,87)=$ $4.02, p<.05, \eta_{\mathrm{p}}^{2}=.04$. Separate analyses for younger and older adults showed significant quadratic time $\times$ training group interactions in the young, in both left precuneus, $F(1,42)=17.54, p<.05, \eta_{\mathrm{p}}^{2}=.30$, and left paracentral lobule, $F(1,42)=11.46, p<.05, \eta_{p}^{2}=.21$, but not in the old age group, $F(1,45)=1.74, n s$, for precuneus and $F(1,45)=.07, n s$, for paracentral lobule.

To further investigate the decrease in the old control group, detected at the more lenient threshold of $p<.001$, we extracted the mean changes in the significant cluster in right middle frontal gyrus and compared the cortical thinning in old controls to changes in this region in old navigators. Old controls exhibited significantly larger decrease in cortical thickness in right middle frontal gyrus between pretest and posttest 1 than old navigators $(t(45)=-2.19, p<.05, d=$ $-.65)$. This difference was no longer reliable at posttest $2(t(45)=$ $-.62, p=.54)$. In young adults, navigators and controls did not show any significant differences in cortical thickness in this region $(t s<1, n s)$.

Again, the mixed 3-way ANOVA, with training, age group, and time as factors on the cluster in the right middle frontal gyrus verified this pattern and revealed a significant quadratic time $\times$ training group interaction, $F(1,87)=4.10, p<.05, \eta_{\mathrm{p}}^{2}=.04$, that was detectable in old adults only $\left(F(1,45)=9.04, p<.05, \eta_{\mathrm{p}}^{2}=.17\right)$. Accordingly, there were significant linear $\left(F(1,87)=5.80, p<.05, \eta_{\mathrm{p}}^{2}=.06\right)$ and quadratic $\left(F(1,87)=5.88, p<.05, \eta_{\mathrm{p}}^{2}=.06\right)$ time $\times$ age group interactions, and a trend for a significant quadratic time $\times$ group $\times$ age group interaction, $F(1,87)=3.92, p=.05, \eta_{\mathrm{p}}^{2}=.04$.

In summary, we found training-related cortical thickening in left precuneus and paracentral lobule in young but not in old navigators. In the old control group, a trend toward cortical thinning in right middle frontal gyrus was observed that was nonexistent in the old navigation group (see Table 2 ). 

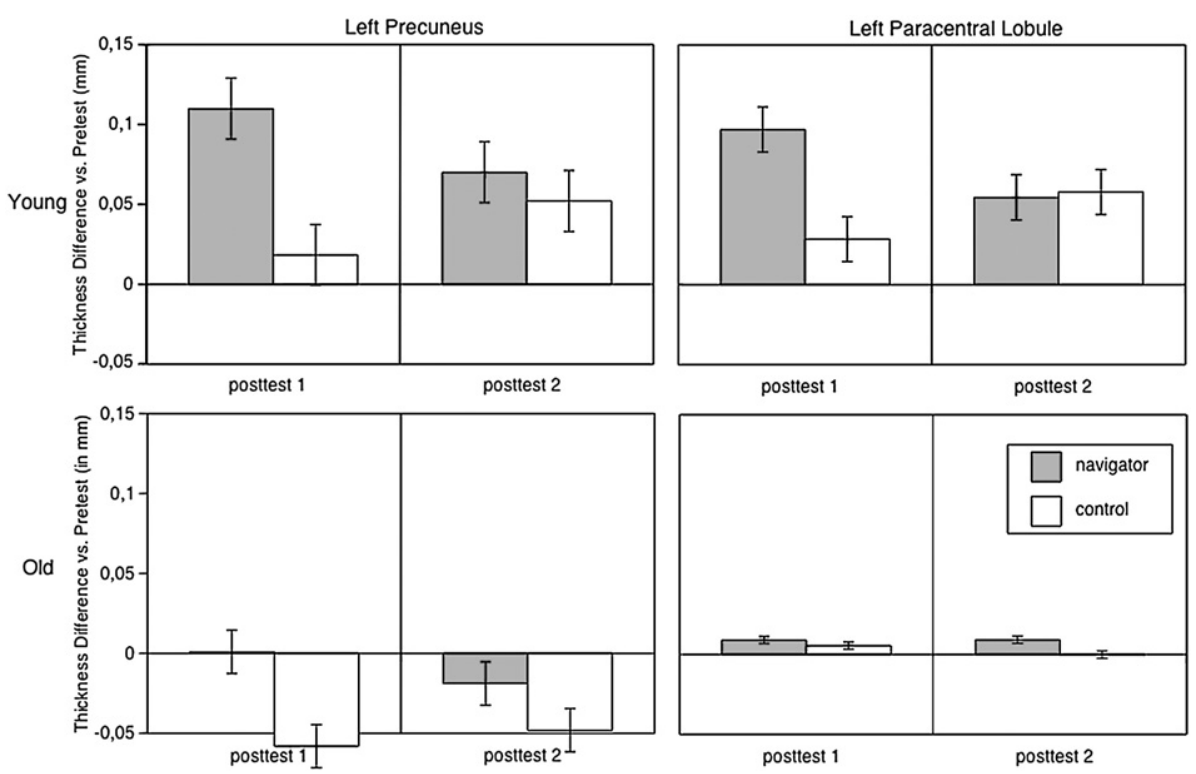

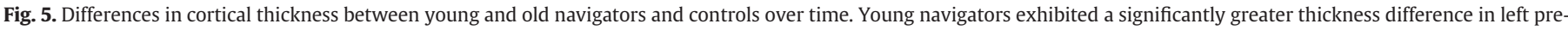

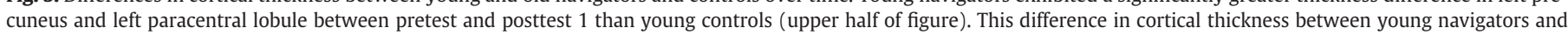

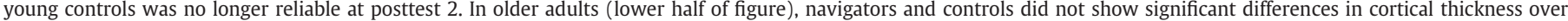
time, neither in precuneus nor in paracentral lobule. In left precuneus, there was a trend for thickness decrease in older controls, but not in older navigators.

\section{Correlations between brain structure changes and behavior}

We did not find any significant correlations between changes in navigation performance and changes in precuneus or paracentral lobule ROIs $(p>.05)$ or any significant relation between changes in navigation performance and vertex-wise whole-brain cortical thickness as computed in FreeSurfer. We also tested for correlations between pretest vertex-wise cortical thickness and behavioral performance at pretest, pretest cortical thickness and behavioral improvement in posttest 1 , and pretest cortical thickness and performance at posttest 1. Again, no correlation was statistically reliable, even at more lenient thresholds.

\section{Discussion}

This study investigated whether human spatial navigation training is associated with changes in cortical thickness. Younger as well as older navigators exhibited large improvements in navigation performance after four months of training, and these improvements were partly maintained four months after termination of training. As expected, older adults generally showed lower performance than younger adults. Younger adults displayed training-related increases in thickness in left precuneus and paracentral lobule. No significant

Table 2

Significant cortical thickness changes in young navigators and old controls between pretest and posttest 1 .

\begin{tabular}{|c|c|c|c|c|c|c|}
\hline \multirow[t]{2}{*}{ Anatomical area } & \multirow[t]{2}{*}{ Hemisphere } & \multicolumn{3}{|c|}{$\begin{array}{l}\text { Talairach } \\
\text { coordinates }\end{array}$} & \multirow[t]{2}{*}{$\mathrm{p}$ value } & \multirow[t]{2}{*}{$\begin{array}{l}\text { Nav }>\text { controls } \\
p<.05\end{array}$} \\
\hline & & $x$ & $y$ & $z$ & & \\
\hline \multicolumn{7}{|c|}{ Increases in young navigation group } \\
\hline $\begin{array}{l}\text { Paracentral } \\
\text { lobule }\end{array}$ & $\mathrm{L}$ & -5 & -32 & 58 & FDR $p<.05$ & $t(42)=3.12$ \\
\hline Precuneus & $\mathrm{L}$ & -7 & -48 & 50 & FDR $p<.05$ & $t(42)=3.43$ \\
\hline $\begin{array}{l}\text { Superior parietal } \\
\text { lobule }\end{array}$ & $\mathrm{L}$ & -32 & -47 & 59 & FDR $p<.05$ & ns \\
\hline \multicolumn{7}{|c|}{ Decreases in old control group } \\
\hline $\begin{array}{l}\text { Middle frontal } \\
\text { gyrus }\end{array}$ & $\mathrm{R}$ & 40 & 30 & 16 & $\begin{array}{l}p<.001 \\
\text { uncorr }\end{array}$ & $t(45)=-2.19$ \\
\hline
\end{tabular}

training-related increases in cortical thickness were observed for older adults. A trend toward decrease in thickness in right middle frontal gyrus was observed in the older control group but, importantly, not in the older navigation group.

The cortical thickening of left precuneus and paracentral lobule in young navigators may constitute a structural neural signature of increased functional usage of this region. Indeed, precuneus and paracentral lobule belong to the parietal cortex and are part of the neural network underlying spatially guided behavior (Colby, 1999; Colby and Goldberg, 1999; Malouin et al., 2003; Selemon and Goldman-Rakic, 1988). The parietal cortex may integrate the perception of immediate space and the spatial orientation of the individual with more distant spatial representations, allowing navigators to represent the route to a goal (Calton and Taube, 2009). Single-neuron recordings revealed that the parietal cortex, in interaction with the hippocampus, plays a critical role in the selection of the most appropriate route between two points (Nitz, 2009). As suggested by Becker and Burgess (2001), the posterior-medial parietal cortex may act in concert with lateral parietal areas in elaborating and translating information about egocentric and allocentric spatial relations, as well as performing higher-order processes such as voluntary shifting of attention and abstract mental imagery (Cavanna and Trimble, 2006). Positron Emission Tomography (PET) has delineated two functional networks engaged during mental simulations of routes: (a) a nonspecific memory network, including the posterior and middle parts of the hippocampal regions, the dorsolateral prefrontal cortex, and the posterior cingulum, and (b) a specific mental navigation network involving the left precuneus, insula, and medial part of the hippocampal regions (Ghaem et al., 1997). It appears that the precuneus plays a central role in a wide spectrum of highly integrated tasks, including visuo-spatial imagery, episodic memory retrieval, and self-referential operations (Cavanna and Trimble, 2006; Margulies et al., 2009), all of which were potentially involved in the present navigation task and thus could have contributed to the training-related volume increase observed in the young.

Taken together, precuneus and paracentral lobule participate in the neural network underlying the complex process of spatial navigation. It is plausible that the increased demand on these regions posed by the enduring spatial navigation training triggered the system to structurally 
adjust to the required functional output in young adulthood. However, given that changes in structure did not correlate with behavioral improvements, it remains unclear whether cortical thickening critically contributed to increased performance. It is possible that we did not have the required power to detect associations between changes (cf. Bonate, 2000; Hertzog et al., 2006). Furthermore, our sample exhibited relatively restricted individual differences in change, thereby further reducing the chances to detect a reliable link between changes in behavior and changes in brain structure. The absence of a behavioral correlate to the changes in cortical thickness underscores the need to investigate the functional relevance of structural changes more closely (Wolbers and Hegarty, 2010).

It is currently not known which neurobiological mechanisms underlie experience-induced increases in human cortical thickness. Possible candidate processes are changes in size of the neuropil or glia, variations in connectivity depending on dendritic and axonal arborization or synaptogenesis, or changes in vascularization (Kempermann et al., 2002; Kronenberg et al., 2006; Roth et al., 2010; Trachtenberg et al., 2002). In the future, other additional imaging methods, such as PET, MR-spectroscopy or Arterial Spin Labeling, may be combined with cortical thickness assessment to delineate the biological substrates of gray matter volume changes.

The effects of navigation training on brain structure were strongly influenced by adult age: Cortical thickening was restricted to the younger navigation group. This finding seems to contradict some previous reports that paint a more optimistic picture of cortical plasticity in old age (Boyke et al., 2008; Engvig et al., 2010). However, the infrequent findings suggesting neuroplasticity of cortical regions in old age should not be overstated; our results serve as a reminder of the well-known age-related decrements in human brain structure (e.g., Jernigan et al., 2001; Raz et al., 2005; Salat et al., 2004). Arguably, these age-related decreases would first need to be attenuated and then reversed in order to pave the way for experience-driven increases in brain structure. This was the pattern found for hippocampal volume in Lövdén et al. (in press). Specifically, in that study the older control groups displayed volume losses approximating previous longitudinal findings of age-related decline in hippocampal volume (Raz et al., 2005), whereas older navigators exhibited stable hippocampal volumes that were maintained four months after termination of training. Despite the fact that the whole-brain analyses of cortical thickness reported here did not reveal significant decreases for the older groups at the conservative threshold of $\operatorname{FDR} p<.05$, there were trends for thickness decreases in left precuneus for older controls but not for older navigators (see lower left panel in Fig. 5). Obviously, this pattern is consistent with that reported for hippocampal volume in the study by Lövdén et al. (in press).

Moreover, at the more liberal and thus rather explorative threshold level of $p<.001$, a similar pattern was observed for right middle frontal gyrus, indicating an age-related cortical thinning in the older control group. Again, this decrease was nonexistent in the old navigation group. The lateral prefrontal cortex, including the middle frontal gyrus, is known to be activated during spatial working memory tasks (Nagel et al., 2009) and in higher-order cognitive control tasks (Miller and Cohen, 2001; Taren et al., 2011). Given that older adults performed less well than younger adults in the spatial navigation task, it is conceivable that the training posed higher demands on working memory and cognitive control in the older adults. This higher demand may have resulted in structural adaptation of the middle frontal gyrus for older adults. The stable frontal cortical thickness in old navigators may therefore reflect attenuated age-related deterioration of gray matter-a deterioration that was visible in the old control group (cf. Lövdén et al., in press).

It should be noted that only men were investigated in this study. This was done to reduce inter-individual differences in navigation strategies (Driscoll et al., 2005; Grön et al., 2000; Sandstrom et al., 1998). However, the assumption that men tend to use on average more allocentric strategies than women (Lövdén et al., 2007) does not hold unequivocally for older persons, who may predominantly rely on egocentric strategies irrespective of sex (Rodgers et al., in press). Hence, it is important to corroborate the findings from the present study with an investigation of possible structural alterations from navigation training in both younger and older women, and with an assessment of navigational strategies in younger and older participants (Gramann et al., 2010).

To conclude, this study shows that performance in a complex spatial navigation task can be substantially improved in younger as well as in older adults, which may have implications for the mobility of older people in their daily lives. Spatial navigation training had a sustainable effect on cortical brain structure of younger adults. Therefore, we were able to extend evidence on experience-driven plasticity in the adult brain (Bengtsson et al., 2005; Cannonieri et al., 2007; Draganski et al., 2004, 2006; Gaser and Schlaug, 2003; Granert et al., 2011; Ilg et al., 2008; Maguire et al., 2006; Münte et al., 2002; Taubert et al., 2010). Finally, our findings confirm the proposition that normal aging reduces the potential for experience-dependent structural alterations in cortical areas (Gruntzendler et al., 2002; Lövdén et al., 2010; Mizhari and Katz, 2003; Trachtenberg et al., 2002; Wagner et al., 2000).

\section{Disclosure statement}

\section{No conflicts of interest.}

\section{Acknowledgments}

Funded by the Max Planck Society; the Sofja Kovalevskaja Award (to ML) administered by the Alexander von Humboldt Foundation and donated by the German Federal Ministry for Education and Research (BMBF); the German Research Council; the BMBF (to UL); the Swedish Research Council; the Swedish Brain Power; and an Alexander von Humboldt Research Award (to LB). Lars Bäckman was also supported by a donation from the af Jochnick Foundation.

During the work on her dissertation, EW has been funded by the International Max Planck Research School "The Life Course: Evolutionary and Ontogenetic Dynamics" (LIFE).

The authors thank Colin Bauer, Daniel Bittner, Marcel Derks, Isabel Dziobek, Gabriele Faust, Martin Kanowski, Jörn Kaufmann, Kristen Kennedy, Shireen Kwiatkowska-Naqvi, Naftali Raz, Karen Rodrigue, Michael Schellenbach, Claus Tempelmann, and all student assistants.

\section{References}

Aguirre, G.K., Detre, J.A., Alsop, D.C., D'Esposito, M., 1996. The parahippocampus subserves topographical learning in man. Cereb. Cortex 6, 823-829. doi:10.1093/cercor/6.6.823.

Antanova, E., Parslow, D., Brammer, M., Dawson, G.R., Jackson, S.H., Morris, R.G., 2009. Age-related neural activity during allocentric spatial memory. Memory 17 (2), 125-143. doi:10.1080/09658210802077348.

Barnes, C., 1979. Memory deficits associated with senescence: a neurophysiological and behavioral study in the rat. J. Comp. Physiol. Psychol. 93 (1), 74-104. doi:10.1037/ h0077579.

Becker, S., Burgess, N., 2001. Modelling spatial recall, mental imagery and neglect. Adv. Neural Inf. Process. Syst. 13, 96-102.

Begega, A., Cienfuegos, S., Rubio, S., Santín, J.L., Miranda, R., Arias, J.L., 2001. Effects of aging on allocentric and egocentric spatial stretegies in the Wistar rat. Behav. Processes 53, 75-85. doi:10.1016/S0376-6357(00)00150-9.

Bengtsson, S.L., Nagy, Z., Skare, S., Forsman, L., Forssberg, H., Ullén, F., 2005. Extensive piano practicing has regionally specific effects on white matter development. Nat. Neurosci. 8 (9), 1148-1150. doi:10.1038/nn1516.

Bird, C.M., Burgess, N., 2008. The hippocampus and memory: insights from spatial processing. Nat. Rev. Neurosci. 9 (3), 182-194. doi:10.1038/nrn2335.

Bohbot, V.D., Lerch, J., Thorndycraft, B., Iaria, G., Zijdenbos, A.P., 2007. Gray matter differences correlate with spontaneous strategies in a human virtual navigation task. J. Neurosci. 27 (38), 10078-10083. doi:10.1523/jneurosci.1763-07.2007.

Bohbot, V.D., Gupta, M., Banner, H., Dahmani, L., 2011. Caudate nucleus-dependent response strategies in a virtual navigation task are associated with lower basal cortisol and impaired episodic memory. Neurobiol. Learn. Mem. 96, 173-180. doi:10.1016/ j.nlm.2011.04.007.

Bonate, P.L., 2000. Analysis of Pretest-Posttest Designs. Chapman \& Hall/CRC, Boca Raton, London, New York, Washington, D.C. 
Boyke, J., Driemeyer, J., Gaser, C., Buchel, C., May, A., 2008. Training-induced brain structure changes in the elderly. J. Neurosci. 28 (28), 7031-7035. doi:10.1523/ jneurosci.0742-08.2008.

Burgess, N., Becker, S., King, J.A., O'Keefe, J., 2001. Memory for events and their spatial context: models and experiments. Philos. Trans. R. Soc. Lond. B Biol. Sci. 356 (1413), 1493-1503. doi:10.1098/rstb.2001.0948.

Burns, P.C., 1999. Navigation and the mobility of older drivers. J. Gerontol. B Psychol. Sci. Soc. Sci. 54B (1), 49-55. doi:10.1093/geronb/54B.1.S49.

Calton, J.L., Taube, J.S., 2009. Where am I and how will I get there from here? A role for posterior parietal cortex in the integration of spatial information and route planning. Neurobiol. Learn. Mem. 91 (2), 186-196. doi:10.1016/j.nlm.2008.09.015.

Cannonieri, G.C., Bonhila, L., Fernandes, P.T., Cendes, F., Li, L.M., 2007. Practice and perfect: length of training and structural brain changes in experienced typists. Neuroreport 18 (10), 1063-1066. doi:10.1097/WNR.0b013e3281a030e5.

Cavanna, A.E., Trimble, M.R., 2006. The precuneus: a review of its functional anatomy and behavioural correlates. Brain 129, 564-583. doi:10.1093/brain/awl004.

Colby, C.L., 1999. Parietal cortex constructs action-orientated spatial representations. In: Burgess, N., Jeffery, K.J., O'Keefe, J. (Eds.), The Hippocampal and Parietal Foundations of Spatial Cognition. Oxford University Press, Oxford, pp. 104-126.

Colby, C.L., Goldberg, M.E., 1999. Space and attention in parietal cortex. Annu. Rev. Neurosci. 22, 319-349. doi:10.1146/annurev.neuro.22.1.319.

Dale, A.M., Fischl, B., Sereno, M.I., 1999. Cortical surface-based analysis. I. Segmentation and surface reconstruction. Neuroimage 9, 179-194. doi:10.1006/nimg.1998.0395.

Draganski, B., Gaser, C., Busch, V., Schuierer, G., Bogdahn, U., May, A., 2004. Neuroplasticity: changes in grey matter induced by training. Nature 427, 311-312. doi:10.1038/ 427311a.

Draganski, B., Gaser, C., Kempermann, G., Kuhn, H.G., Winkler, J., Büchel, C., May, A., 2006. Temporal and spatial dynamics of brain structure changes during extensive learning. J. Neurosci. 27 (23), 6314-6317. doi:10.1523/JNEUROSCI.4628-05.2006.

Driscoll, I., Hamilton, D.A., Yeo, R.A., Brooks, W.M., Sutherland, R.J., 2005. Virtual navigation in humans: the impact of age, sex, and hormones on place learning. Horm. Behav. 47 (3), 326-335. doi:10.1016/j.yhbeh.2004.11.013.

Ekstrom, A.D., Kahana, M.J., Caplan, J.B., Fields, T.A., Isham, E.A., Newman, E.L., Fried, I. 2003. Cellular networks underlying human spatial navigation. Nature 425, 184-188. doi:10.1038/nature01964.

Engvig, A., Fjell, A.M., Westlye, L.T., Moberget, T., Sundseth, O., Larsen, V.A., Walhovd, K.B., 2010. Effects of memory training on cortical thickness in the elderly. Neuroimage 52 (4), 1667-1676. doi:10.1016/j.neuroimage.2010.05.041.

Fischl, B., Dale, A.M., 2000. Measuring the thickness of the human cerebral cortex from magnetic resonance images. Proc. Natl. Acad. Sci. U. S. A. 97, 11050-11055. doi:10.1073/pnas.200033797.

Fischl, B., Salat, D.H., van der Kouwe, A.J., Makris, N., Segonne, F., T.Q.B., Dale, A.M. 2004a. Sequence-independent segmentation of magnetic resonance images. Neuroimage 23, 69-84. doi:10.1016/j.neuroimage.2004.07.016.

Fischl, B., van der Kouwe, A.J., Destrieux, C., Halgren, E., Segonne, F., Salat, D.H., Dale, A.M., 2004b. Automatically parcellating the human cerberal cortex. Cereb. Cortex 14, 11-22. doi:10.1093/cercor/bhg087.

Gaser, C., Schlaug, G., 2003. Gray matter differences between musicians and nonmusicians. Ann. N. Y. Acad. Sci. 999, 514-517. doi:10.1196/annals.1284.062.

Ghaem, O., Mellet, E., Crivillo, F., Tzourio, N., Mazoyer, B., Berthoz, A., Denis, M., 1997. Mental navigation along memorized routes activates the hippocampus, precuneus, and insula. Neuroreport 8 (3), 739-744. doi:10.1097/00001756-199702100-00032.

Gramann, K., Onton, J., Riccobon, D., Mueller, H.J., Bradins, S., Makeig, S., 2010. Human brain dynamics accompanying use of egocentric and allocentric reference frames during navigation. J. Cogn. Neurosci. 22 (12), 2836-2849. doi:10.1162/jocn.2009.21369.

Granert, O., Peller, M., Gaser, C., Groppa, S., Hallett, M., Knutzen, A., Siebner, H.R., 2011 Manual activity shapes structure and function in contralateral human motor hand area. Neuroimage 54 (1), 32-41. doi:10.1016/j.neuroimage.2010.08.013.

Grön, G., Wunderlich, A., Tomczak, R., Riepe, M.W., 2000. Brain activation during human navigation: gender-different neural networks as substrate of performance. Nat. Neurosci. 3 (4), 404. doi:10.1038/73980.

Gruntzendler, J., Kasthuri, N., Gan, W.B., 2002. Long-term dendritic spine stability in the adult cortex. Nature 420, 812-816. doi:10.1038/nature01276.

Han, X., Jovicich, J., Salat, D.H., van der Kouwe, A.J., Quinn, B., Czanner, S., Fischl, B., 2006. Reliability of MRI-derived measurements of human cerebral cortical thickness: the effects of field strenght, scanner upgrade and manufacturer. Neuroimage 32, 180-194. doi:10.1016/j.neuroimage.2006.02.051.

Hartley, T., Bird, C.M., Chan, D., Cipolotti, L., Husain, M., Vargha-Khadem, F., Burgess, N., 2007. The hippocampus is required for short-term topographical memory in humans. Hippocampus 17 (1), 34-48. doi:10.1002/hipo.20240.

Hertzog, C., Lindenberger, U., Ghisletta, P., Oertzen, T., 2006. On the power of multivariate latent growth curve models to detect correlated change. Psychol. Methods 11 (3), 244-252. doi:10.1037/1082-989X.11.3.244

Hertzog, C., Kramer, A.F., Wilson, R.S., Lindenberger, U., 2009. Enrichment effects on adult cognitive development: can the functional capacity of older adults be preserved and enhanced? Psychol. Sci. Public Interest 9 (1), 1-65.

Iaria, G., Petrides, M., Dagher, A., Pike, B., Bohbot, V.D., 2003. Cognitive strategies dependent on the hippocampus and caudate nucleus in human navigation: variablity and change with practice. J. Neurosci. 23 (13), 5945-5952.

Ilg, R., Wohlschläger, A.M., Gaser, C., Liebau, Y., Dauner, R., Wöller, A., Mühlau, M., 2008. Gray matter increase induced by practice correlates with task-specific activation: a combined functional and morphometric magnetic resonance imaging study. J. Neurosci. 28 (16), 4210-4215. doi:10.1523/JNEUROSCI.5722-07.2008.

Ingram, D.K., 1988. Complex maze learning in rodents as a model of age-related memory impairment. Neurobiol. Aging 9 (5-6), 475-485. doi:10.1016/S01974580(88)80101-5.
Jernigan, T.L., Archibald, S.L., Fennema-Notestine, C., Gamst, A.C., Stout, J.C., Bonner, J., Hesselink, J.R., 2001. Effects of age on tissues and regions of the cerebrum and cerebellum. Neurobiol. Aging 22 (4), 581-594. doi:10.1016/s0197-4580(01)00217-2.

Jovicich, J., Czanner, S., Greve, D.N., Haley, E., van der Kouwe, A.J., Gollub, R., Dale, A. 2006. Reliability in multi-site structural MRI studies: effects of gradient nonlinearity correction on phantom and human data. Neuroimage 30, 436-443. doi:10.1016/j.neuroimage.2005.09.046.

Kempermann, G., Gast, D., Gage, F.H., 2002. Neuroplasticity in old age: sustained fivefold induction of hippocampal neurogenesis by long-term environmental enrichment. Ann. Neurol. 52, 135-143. doi:10.1002/ana.10262.

Kronenberg, G., Bick-Sander, A., Bunk, E., Wolf, C., Ehninger, D., Kempermann, G., 2006. Physical exercise prevents age-related decline in precursor cell activity in the mouse dentate gyrus. Neurobiol. Aging 27, 1505-1513. doi:10.1016/j.neurobiolaging.2005 09.016 .

Kuperberg, G.R., Broome, M.R., McGuire, P.K., David, A.S., Eddy, M., Ozawa, F., Fischl, B. 2003. Regionally localized thinning of the cerebral cortex in schizophrenia. Arch. Gen. Psychiatry 60 (9), 878-888. doi:10.1001/archpsyc.60.9.878.

Lehrl, S., Merz, J., Burkard, G., Fischer, B., 1991. Manual zum MWT-a. Perimed, Erlangen, Germany.

Lerch, J.P., Yiu, A.P., Martinez-Canabal, A., Pekar, T., Bohbot, V.D., Frankland, P.W., Henkelman, R.M., Josselyn, S.A., Sled, J., 2011. Maze training in mice induces MRI-detectable brain shape changes specific to the type of learning. Neuroimage 54, 2086-2095. doi:10. 1016/j.neuroimage.2010.09.086

Lövdén, M., Ghisletta, P., Lindenberger, U., 2005a. Social participation attenuates decline in perceptual speed in old and very old age. Psychol. Aging 20 (3), 423-434 doi:10.1037/0882-7974.20.3.423.

Lövdén, M., Schellenbach, M., Grossman-Hutter, B., Krüger, A., Lindenberger, U., 2005b. Environmental topography and postural control demands shape aging-associated decrements in spatial naviagtion performance. Psychol. Aging 20 (4), 683-694. doi:10.1037/0882-7974.20.4.683.

Lövdén, M., Herlitz, A., Schellenbach, M., Grossman-Hutter, B., Krüger, A., Lindenberger U., 2007. Quantitative and qualitative sex differences in spatial navigation. Scand. J. Psychol. 48 (5), 353-358. doi:10.1111/j.1467-9450.2007.00582.x.

Lövdén, M., Bäckman, L., Lindenberger, U., Schaefer, S., Schmiedek, F., 2010. A theoretical framework for the study of adult cognitive plasticity. Psychol. Bull. 136 (4) 659-676. doi:10.1037/a0020080.

Lövdén, M., Schaefer, S., Noack, H., Kanowski, M., Kaufmann, J., Tempelmann, C., Bäckman, L., 2011. Performance-related increases in hippocampal N-acetylaspartate (NAA) induced by spatial navigation training are restricted to BDNF val homozygotes. Cereb. Cortex 21 (6), 1435-1442. doi:10.1093/cercor/bhq230.

Lövdén, M., Schaefer, S., Noack, H., Bodammer, N.C., Kühn, S., Heinze, H.-J., Lindenberger, U. (in press). Spatial navigation training protects the hippocampus against age-related changes during early and late adulthood. Neurobiol. Aging.

Maguire, E.A., Burgess, N., Donnett, J.G., Frackowiak, R.S.J., Frith, C.D., O'Keefe, J., 1998. Knowing where and getting there: a human navigation network. Science 280 (5365), 921-924. doi:10.1126/science.280.5365.921.

Maguire, E.A., Gadian, D.G., Johnsrude, I.S., Good, C.D., Ashburner, J., Frackowiak, R.S., Frith, C.D., 2000. Navigation-related structural change in the hippocampi of taxi drivers. Proc. Natl. Acad. Sci. U. S. A. 97 (8), 4398-4403. doi:10.1073/pnas.070039597.

Maguire, E.A., Woollett, K., Spiers, H.J., 2006. London taxi drivers and bus drivers: a struc tural MRI and neuropsychological analysis. Hippocampus 16 (12), 1091-1101. doi:10.1002/hipo.20233.

Mahmood, O., Adamo, D., Briceno, E., Moffat, S.D., 2009. Age differences in visual path integration. Behav. Brain Res. 205 (1), 88-95. doi:10.1016/j.bbr.2009.08.001.

Malouin, F., Richards, C.L., Jackson, P.L., Dumas, F., Doyon, J., 2003. Brain activations during motor imagery of locomotor-related tasks: a PET study. Hum. Brain Mapp. 19 (1), 47-62. doi:10.1002/hbm.10103.

Margulies, D.S., Vincent, J.L., Kelly, C., Lohmann, G., Uddin, L.Q., Biswal, B.B., Petrides, M., 2009. Precnuneus shares intrinsic functional architecture in humans and monkeys. Proc. Natl. Acad. Sci. U. S. A. 106 (47), 20069-20074. doi:10.1073/pnas.0905314106.

McLay, R.N., Freeman, S.M., Harlan, R.E., Kastin, A.J., Zadina, J.E., 1999. Tests used to as sess the cognitive abilities of aged rats: their relation to each other and to hippocampal morphology and neurotrophin expression. Gerontology 45 (3), 143-155. doi:10.1159/000022077.

Miller, E.K., Cohen, J.D., 2001. An integrative theory of prefrontal cortex function. Annu. Rev. Neurosci. 24, 167-202. doi:10.1146/annurev.neuro.24.1.167.

Mizhari, A., Katz, L.C., 2003. Dendritic stability in the adult olfactory bulb. Nat. Neurosci. 6, 1201-1207. doi:10.1038/nn1133.

Moffat, S.D., Zonderman, A.B., Resnick, S.M., 2001. Age differences in spatial memory in a virtual environment navigation task. Neurobiol. Aging 22 (5), 787-796. doi:10.1016/S0197-4580(01)00251-2.

Moffat, S.D., Elkins, W., Resnick, S.M., 2006. Age differences in the neural systems supporting human allocentric spatial navigation. Neurobiol. Aging 27 (7), 965-972. doi:10.1016/j.neurobiolaging.2005.05.011.

Moffat, S.D., Kennedy, K.M., Rodrigue, K.M., Raz, N., 2007. Extrahippocampal contributions to age differences in human spatial navigation. Cereb. Cortex 17 (6), 1274-1282. doi:10.1093/cercor/bhl036.

Münte, T.F., Altenmüller, E., Jäncke, L., 2002. The musician's brain as a model of neuroplasticity. Nat. Rev. Neurosci. 3 (6), 473-478.

Nagel, I.E., Preuschhof, C., Li, S.-C., Nyberg, L., Bäckman, L., Lindenberger, U., Heekeren, H.R., 2009. Performance level modulates adult age differences in brain activation during spatial working memory. Proc. Natl. Acad. Sci. U. S. A. 106 (52), 22552-22557. doi:10.1073/pnas.0908238106

Newman, M.C., Kaszniak, A.W., 2000. Spatial memory and aging: performance on a human analog of the morris water maze. Aging Neuropsychol. Cogn. 7 (2) 86-93. doi:10.1076/1382-5585(200006)7:2;1-U;FT086. 
Nitz, D., 2009. Parietal cortex, navigation, and the construction of arbitrary reference frames for spatial information. Neurobiol. Learn. Mem. 91 (2), 179-185. doi:10.1016/ j.nlm.2008.08.007.

O'Keefe, J., Burgess, N., 1996. Geometric determinants of the place fields of hippocampal neurons. Nature 381, 425-428. doi:10.1038/381425a0.

O'Keefe, J., Nadel, L., 1978. The Hippocampus as A Cognitive Map. Clarendon, Oxford.

Raz, N., Lindenberger, U., Rodrigue, K.M., Kennedy, K.M., Head, D., Williamson, A., Acker J.D., 2005. Regional brain changes in aging healthy adults: general trends, individua differences and modifiers. Cereb. Cortex 15 (11), 1676-1689. doi:10.1093/cercor/ bhi044.

Rodgers, M.K., Sindone III, J. A., Moffat, S.D. (in press). Effects of age on navigation strategy Neurobiol. Aging. doi: 10.1016/j.neurobiolaging.2010.07.021.

Rosas, H.D., Liu, A.K., Hersch, S., Glessner, M., Ferrante, R.J., Salat, D.H., et al., 2002. Regional and progressive thinning of the cortical ribbon in Huntington's disease. Neurology 58, 695-701 PMid:11889230.

Roth, T.C., Brodin, A., Smulders, T.V., LaDage, L.D., Pravosudov, V.V., 2010. Is bigger always better? A critical appraisal of the use of volumetric analysis in the study of the hippocampus. Philos. Trans. R. Soc. Lond. B Biol. Sci. 365 (1542), 915-931. doi:10.1098/ rstb.2009.0208.

Salat, D.H., Buckner, R.L., Snyder, A.Z., Greve, D.N., Desikan, R.S.R., Busa, E., Fischl, B. 2004. Thinning of the cerebral cortex in aging. Cereb. Cortex 14 (7), 721-730. doi:10.1093/cercor/bhh032.

Sandstrom, N.J., Kaufman, J., Huettel, S.A., 1998. Males and females use different distal cues in a virtual environment navigation task. Cogn. Brain Res. 6 (4), 351-360. doi:10.1016/s0926-6410(98)00002-0.

Segonne, F., Dale, A.M., Busa, E., Glessner, M., Salat, D.H., Hahn, H.K., Fischl, B., 2004. A hybrid approach to the skull stripping problem in MRI. Neuroimage 22 (1060-1075). doi:10.1016/j.neuroimage.2004.03.032.

Selemon, L. Goldman-Rakic, P. 1988. Common cortical and subcortical targets of the dorsolateral prefrontal and posterior parietal cortices in the rhesus monkey: evidence for a distributed neural network subserving spatially guided behavior. J. Neurosci. 8 (11), 4049-4068 PMid:2846794.

Taren, A.A., Venkatraman, V., Huettel, S.A., 2011. A parallel functional topography between medial and lateral prefrontal cortex: evidence and implications for cogni- tive control. J. Neurosci. 31 (13), 5026-5031. doi:10.1523/JNEUROSCI.576210.2011.

Taubert, M., Draganski, B., Anwander, A., Müller, K., Horstmann, A., Villringer, A., Ragert, P., 2010. Dynamic properties of human brain structure: learning-related changes in cortical areas and associated fiber connections. J. Neurosci. 30 (35), 11670-11677. doi:10.1523/JNEUROSCI.2567-10.2010.

Trachtenberg, J.T., Chen, B.E., Knott, G.W., Feng, G., Sanes, J.R., Welker, E., Svoboda, K., 2002. Long-term in vivo imaging of experience-dependent synaptic plasticity in adult cortex. Nature 420, 788-794. doi:10.1038/nature01273.

van Praag, H., Kempermann, G., Gage, F.H., 2000. Neural consequences of environmental enrichment. Nat. Rev. Neurosci. 1 (3), 191-198. doi:10.1038/35044558.

Wagner, A.P., Schmoll, H., Badan, I., Platt, D., Kessler, C., 2000. Brain plasticity: to what extent do aged animals retain the capacity to coordinate gene activity in response to acute challenges. Exp. Gerontol. 35 (9-10), 1211-1227. doi:10.1016/s0531-5565(00)00154-6.

Wang X, Bauer, W. Chiaia, N., Dennis, M. Gerken, M., Hummel, J., Kane, J., Kenmuir C. Khuder, S., Lane, R., Mooney, R., Bazeley, P., Apkarian, V., Wall, J., 2008. Longitudinal MRI evalations of human global cortical thickness over minutes to weeks. Neurosci. Lett. 441, 145-148. doi:10.1016/j.neulet.2008.06.013.

Wechsler, D., 1981. Manual for the Wechsler Adults Intelligence Scale-Revised. Psychological Corporation, New York.

Wilkniss, S.M., Jones, M.G., Korol, D.L., Gold, P.E., Manning, C.A., 1997. Age-related differences in an ecologically based study of route learning. Psychol. Aging 12 (2), 372-375. doi:10.1037/0882-7974.12.2.372.

Wolbers, T., Hegarty, M., 2010. What determines our navigational abilities? Trends Cogn. Sci. 14 (3), 138-146. doi:10.1016/j.tics.2010.01.001

Wolbers, T., Wiener, J.M., Mallot, H.A., Büchel, C., 2007. Differential recruitment of the hippocampus, medial prefrontal cortex, and the human motion complex during path integration in humans. J. Neurosci. 27 (35), 9408-9416. doi:10.1523/jneurosci.214607.2007.

Wonderlick, J.S., Ziegler, D.A., Hosseini-Varnamkhasti, P., Locascio, J.J., Bakkour, A., van der Kouwe, A., Triantafyllou, C., Corkin, S., Dickerson, B.C., 2009. Reliability of MRIderived cortical and subcortical morphometric measures: effects of pulse sequence, voxel geometry, and parallel imaging. Neuroimage 44, 1324-1333. doi:10.1016/j.neuroimage.2008.10.037 